\title{
Bare Plurals in Spanish are Interpreted as Properties*
}

\section{Louise McNally}

Universitat Pompeu Fabra. Departament de Traducció i Filologia

La Rambla, 30-32. E-08002 Barcelona

louise.mcnally@upf.edu

\begin{abstract}
In this paper, I argue that bare plural noun phrases in Spanish unambiguously denote properties of individuals. I begin by using evidence from their incompatibility with kind-level predicates to show that Spanish bare plurals do not denote kinds. I then point to crucial ways in which their interaction with quantifiers is unlike that of other indefinite NPs (specifically, they have obligatory narrowest scope and cannot contribute the main restriction on a quantifier), and I conclude that bare plurals must therefore have a different semantics from other indefinites. I present a formal semantic analysis which allows for any verbal predicate in Spanish to combine with a propertytype noun phrase, showing how this analysis can also account for certain facts involving discourse anaphora to bare plurals. Finally, I discuss the advantages of the proposed analysis over those which try to maintain a uniform semantics for bare plurals and indefinites and indicate some of the general implications of the proposal.
\end{abstract}

Key words: semantics, properties, bare nominals, incorporation

\section{Table of Contents}

Preface 5. Conclusion: some final support for

1. The problem

2. Distinguishing properties the property analysis of BPs

Appendix

of Spanish BPs

References

\section{Analysis}

4. Why not treat BPs as 'special' indefinites?

* I am grateful to audiences at SUNY Buffalo, UC Santa Cruz, UC San Diego, and Stanford University for the opportunity to present this material and for useful comments. This work has also benefitted from discussion with Donka Farkas, Bill Ladusaw, Kari Swingle, and especially Josep M. Fontana, as well as from comments by two reviewers for the Catalan Journal of Linguistics. 


\section{Preface}

This paper was originally presented at the Formal Grammar Conference at the European Summer School in Logic, Language and Information (ESSLLI) in Barcelona in 1995; a written version appeared in the proceedings of the conference, edited by Richard Oehrle and Glyn Morrill and distributed during ESSLLI as a spiral-bound set of photocopies. Under normal circumstances I would have subsequently revised the paper for publication; however, the circumstances were not normal - I was in the middle of moving to Barcelona, with all of the personal and professional changes and tràmits that that entailed - and the paper ended up abandoned, though it has circulated actively as an unpublished manuscript.

I have chosen to leave the paper essentially in its original form for two reasons. First, it has been cited often enough that it seemed reasonable to make it available in a properly published form. But second and more importantly, given the amount of research that has been done on property-type arguments and on bare nominals in the years since the paper was written, revising it would have meant starting from scratch and writing an entirely new paper or, more likely, set of papers.

The main theoretical goal of the paper was to present a formalization - the first, that I know of, together with that presented in Van Geenhoven (1995) - of the intuition that property-type nominals can systematically appear in argument positions normally occupied by referential or quantificational NPs. This formalization has since become familiar in natural language semantics largely through Van Geenhoven's work and some joint work of ours (e.g. McNally and Van Geenhoven 1997, Van Geenhoven and McNally, in press) under the term semantic incorporation. However, there are now two important alternative compositional semantic treatments of property-type arguments, namely those in Farkas and de Swart (2003) and Chung and Ladusaw (2004). Carrying out a comprehensive comparison of these three approaches to handling property-type arguments is a pending task, but one that would have gone well beyond the scope of the work presented here.

It would also have made little sense to revise substantially what is said here about Spanish bare plurals, given the large body of research on the semantics of bare nominals in the Romance languages has been carried out over the last decade. Perhaps the most comprehensive discussion of Spanish specifically appears in Bosque (1996) and the references cited there. An exhaustive study of the descriptive and theoretical issues, not only for Spanish but for the Romance languages more generally, has been conducted over a number of years by Dobrovie-Sorin and Laca (e.g. Laca 1996, Dobrovie-Sorin 1997, Dobrovie-Sorin and Laca 1998, and most notably Dobrovie-Sorin and Laca 2003, the last of these with a comprehensive bibliography). There is little that I could have added to what has already been said in these works.

The proposal that bare nominals in the Romance languages denote properties when they appear in argument positions is not uncontroversial. Chierchia (1998) offers several arguments that such bare nominals denote kinds, and not properties. Some of these arguments have been questioned or refuted in e.g. Van Geenhoven (2000), Chung (2000), and Dobrovie-Sorin and Laca (2003); Krifka (2003) sug- 
gests a compromise position between those adovcated by Chierchia and these latter researchers. The complexity of the data discussed in these works clearly suggests that this is an area in need of additional, very detailed empricial investigation, and not only on the Romance languages.

Though the present paper has not been changed substantially, I have made some minor modifications. I have corrected various errors, changed examples or bits of text to improve readability, added a couple of footnotes (indicated as new in the text), suppressed some others, and updated the references, a number of which were originally cited as manuscripts and have since been published, in some cases in substantially revised form.

\section{The problem}

In English, Spanish, and a number of other languages with article systems, both bare nominals and nominals marked with indefinite determiners ${ }^{1}$ have similar distributions, and both have what appear to be existential interpretations in certain linguistic contexts. For example, all of the English examples in (1), and their Spanish counterparts in (2), have a reading truth conditionally equivalent to (3): ${ }^{2}$

(1) a. Martha bought an orange.

b. Martha bought some oranges.

c. Martha bought oranges.

(2) a. Marta compró una naranja.

Marta bought a.sg orange

b. Marta compró unas naranjas.

Marta bought a.pl oranges

c. Marta compró naranjas.

Marta bought oranges

(3) $\quad(\exists x$ : orange $(x))[\operatorname{bought}(\mathrm{m}, x)]$

Although Carlson's (1977) classic analysis of bare plurals (BPs) treated them as unambiguously kind-denoting (in contrast to indefinite singular noun phrases,

1. Hereafter, the term 'indefinites' will be used to refer to nominals which carry some kind of determiner, and will exclude determinerless nominals. Throughout this paper the term 'noun phrase' (NP) will be used purely descriptively - I will not address the issue of whether nominals carrying a determiner are better analyzed as NPs or Determiner Phrases.

2. Abbreviations in the interlinear translations are: $\mathrm{sg}=$ singular, $\mathrm{pl}=$ plural, acc $=$ accusative, dat $=$ dative, inf $=$ infinitive, imp = imperfect, subj = subjunctive, cond = conditional. Unless otherwise marked, all verbs are indicative and any past tense is preterite (as opposed to imperfect). All verbs agree with their subjects in person and number, and in general determiners and adjectives agree with the nouns they modify in number and gender. 
which were given a more complicated analysis), in at least one major subpart of the recent formal syntax and semantics literature it has been widely assumed (following e.g. Kratzer 1995, Diesing 1992, Wilkinson 1991) that BPs and indefinites can both be interpreted as 'variables' (see Kamp 1984, Heim 1982 for slightly different implementations). Though this analysis improves in several ways on Carlson's original proposal, assigning BPs and indefinites to the same semantic type predicts that, all things being equal, either the two sorts of NPs should have identical semantic properties, or else there should be a principled explanation for any differences between them.

In the case of Spanish, this prediction is incorrect. The goal of this paper is therefore to argue that the differences between Spanish BPs and indefinites follow naturally if we posit a simple difference in semantic type between the two sorts of NPs: specifically, I argue that Spanish BPs are unambiguously interpreted as properties, while this is not so for indefinites. This analysis is much in the spirit of Carlson's proposal and reflects a long-held, if never fully formalized, intuition about the semantics of Spanish BPs (see Alonso 1954, Masullo 1992, Laca 1996, Bosque 1996 and references cited there; contrast Chierchia 1998 for a different position on Italian). In contrast, I will make no particular claims concerning indefinites in this paper, other than that, unlike BPs, they are not unambiguously interpreted as properties. For present purposes I will assume that they can be given the same treatment proposed for English indefinites in Heim (1982).

The paper proceeds as follows. In section 2, I describe two essential differences between BPs and indefinites in Spanish. An analysis of these facts is presented in section 3. In section 4, I show why the proposed analysis is more successful than one which does not posit a type difference between BPs and indefinites. Section 5 contains some concluding comments on the implications of the analysis.

\section{Distinguishing properties of Spanish BPs}

\subsection{Preface: Differences between Spanish and English BPs}

In order to situate the reader already familiar with the English facts, let me point out two differences between Spanish and English BPs. First, while English BPs can denote kinds (see (4)), BPs in Spanish and other Romance languages cannot (as seen in (5); (5b) is from Laca 1996: 262):

(4) Tigers are becoming extinct in India.

a. En la India se están extinguiendo los tigres. in the India se are becoming-extinct the tigers 'Tigers are becoming extinct in India.'

b. *En la India se están extinguiendo tigres. in the India se are becoming-extinct tigers 
Thus, in claiming that Spanish BPs are interpreted as properties, I am committed to the position that a property is distinct from a kind. While it will be clear below how I distinguish the two formally, I will have nothing to say about the substantive nature of the distinction here.

Spanish BPs also lack the 'functional' reading discussed at length for English in Condoravdi (1994), and illustrated in (6a). This reading is intuitively universal but not generic: the BP in (6a) refers to all of the union representatives at the factory (as opposed to just some of them)-thus, is universal as opposed to existential, but it is not generic because it does not refer to all union representatives in general. To express this reading in Spanish, a definite plural NP must be used in place of the $\mathrm{BP}^{3}$ (compare the translations of $(6 \mathrm{a})$ in $(6 \mathrm{~b}, \mathrm{c})$, where the BP, if acceptable at all, ${ }^{4}$ gives rise only to a 'weak' existential interpretation):

(6) a. Last week Nissan announced that it would lay off one-third of its employees at its Barcelona factory. Union representatives have protested vehemently.

b. La semana pasada Nissan anunció que despediría un tercio de the week passed Nissan announced that fire.cond one third of sus empleados en Barcelona. Los representantes sindicales han its employees in Barcelona. the representatives syndical have protestado enérgicamente.

protested energetically.

c. ...??Representantes sindicales han protestado enérgicamente. representatives syndical have protested energetically.

A third difference between Spanish and English will be evident in the data below.

\subsection{Spanish BP/indefinite contrasts}

For now, I will focus on two differences between the behavior of BPs and indefinites in Spanish. First, BPs must take narrowest possible scope with respect to any other operators in the same clause, including negation, intensional predicates, and modals: All of the (b) examples below are unambiguously assigned the narrow scope (d) readings. In contrast, indefinites may take variable scope; the (a) examples are all interpretable with either the wide scope (c) or narrow scope (d) readings

3. For this reason it is tempting to try to relate the absence of the functional reading in Spanish to the absence of the kind reading, though Condoravdi (personal communication) has expressed pessimism on this point. I refer the reader to her work for additional discussion.

4. There is a rather strong preference in Spanish for putting BPs postverbally except in certain discourse contexts (see e.g. Laca 1994 for cases where they can appear preverbally), which makes sentences such as (6c) sound unnatural. Nonetheless, according to the speakers I consulted, this particular sentence sounds even worse with the BP in postverbal position. The fact that it is difficult to construct felicitous, natural-sounding examples with BPs which could even be candidates for the functional reading underscores the fact that this reading is not expressed in Spanish by BPs at all. 
$((7 a, b)$ and (8a,b) are from Laca 1996:253,254; see Carlson 1977 and Wilkinson 1991 for similar contrasts in English):

(7) a. A la reunión no asistieron algunos profesores. (c or d) at the meeting not attended some.pl professors 'The meeting was not attended by some professors.'

b. A la reunión no asistieron profesores. (d only)

c. $(\exists x: \operatorname{professor}(x))[\neg \operatorname{attend}(x, \mathrm{~m})]$

d. $\neg(\exists x: \operatorname{professor}(x))[\operatorname{attend}(x, \mathrm{~m})]$

(8) a. María cree que Sara ha robado unos libros. Maria believes that Sara has stolen a.pl books

(c or d) 'Maria believes that Sara has stolen some books.'

b. María cree que Sara ha robado libros. (d only)

c. $(\exists \mathrm{x}: \operatorname{book}(\mathrm{x}))\left[\operatorname{believe}\left(\mathrm{m},{ }^{\wedge} \operatorname{stole}(\mathrm{s}, \mathrm{x})\right)\right]$

d. $\operatorname{believe}(\mathrm{m}, \wedge(\exists x: \operatorname{book}(x))[\operatorname{stole}(\mathrm{s}, x)])$

(9) a. Hoy Juana tiene que leer unos artículos. (c or d) Today Juana has that read.inf a.pl articles 'Today Juana has to read some articles.'

b. Hoy Juana tiene que leer artículos. (d only)

c. $(\exists x: \operatorname{article}(x))[\square[\operatorname{read}(\mathrm{j}, x)]]$

d. $\square(\exists x: \operatorname{article}(x))[\operatorname{read}(\mathrm{j}, x)]$

A second difference between bare plurals and indefinites in Spanish is that bare plurals cannot supply the primary restriction on adverbial quantification over individuals, ${ }^{5}$ while indefinites can. For instance, the indefinite in (10a) naturally expresses a generalization about members of parliament, as in (10b).

(10) a. Un miembro del parlamento trabaja normalmente ocho horas a.sg member of-the parliament work normally ocho hours al día. to-the day.

'A member of parliament normally works eight hours per day.'

b. (normally $x: \operatorname{mp}(x))[8 \mathrm{hrs} / \operatorname{day}(\operatorname{work}(x))]$

5. If one takes the position that adverbs necessarily quantify over eventualities or cases, then this quantification could perhaps alternatively be described as being over equivalence classes of cases which are distinguished by the identity of some participant. However, for simplicity, I will talk as if adverbs can quantify over individuals. See e.g. de Swart (1993) on adverbial quantification. 
In contrast, (11a) with the BP can only express quantification over some set of contextually-determined situations, and not over members of parliament (see (11b), where $C R$ stands for a contextual restriction on the domain of situations). In other words, (11a) would be false in a situation in which 80 out of 100 members of parliament have eaten at La Panadella restaurant, but only one time each, while the vast majority of the time, the meals eaten by members of parliament are eaten at the bar in the train station:

(11) a. Miembros del parlamento comen a menudo en La Panadella. members of-the parliament eat often in La Panadella 'Members of parliament often eat at La Panadella.'

b. (often $e: C R(e))[(\exists x$ : member-parliament $(x))[\operatorname{eat}(x, \mathrm{p}, e)]]$

In this respect, Spanish BPs appear to contrast with English BPs; both sentences in (12) have a reading that appears to express a generalization about welltrained dogs:

(12) a. A well-trained dog always sits quietly.

b. Well-trained dogs always sit quietly.

To summarize, we have seen so far that Spanish BPs contrast with indefinites in two ways: (1) bare plurals must take narrow scope with respect to any operators in the sentence, while indefinites are not limited in their scope possibilities; and (2) bare plurals cannot contribute the primary restriction on adverbial quantification over individuals, while indefinites can.

\section{Analysis}

I will embed the analysis of these facts in a slightly modified version of Heim's (1982) File Change Semantics (FCS). In FCS, like other theories of dynamic interpretation (e.g. DRT, Kamp 1984; Dynamic Montague Grammar, Groenendijk and Stockhof 1990), the semantic value of a sentence - its context change potential is characterized as its ability to affect the shared assumptions of the participants within a conversational context $C$. Here, the context change potential for a sentence will be a function from 'files' (i.e. discourse models) to files, where a file for a context $C$ is a pair $\langle\operatorname{Dom}(C), \operatorname{Sat}(C)\rangle . \operatorname{Dom}(C)$ is treated here as a set of indexed variables (corresponding to referents in the domain of discourse); $\operatorname{Sat}(C)$, as the set of pairs of possible worlds and variable assignment functions $\langle w, g\rangle$ such that $\langle w, g\rangle$ satisfies all of the sentences in C. Truth can in turn be defined in terms of satisfaction: A sentence $S$ is true in a model $M$ and world $w$ with respect to the file for a context $C$ iff there is some $g$ such that $\langle w, g\rangle$ is an element of Sat $(C+S)$. Specific interpretation rules will be provided below; see Heim (1982) for additional details.

The assumptions underlying the analysis can be summarized as follows. First, as stated above, Spanish BPs will be interpreted unambiguously as properties. How 
exactly properties are characterized is not crucial for my purposes, other than that they be kept distinct from kinds. In order to avoid having to introduce a lot of formal machinery, I will treat them in a familiar way as functions from indices to sets of individuals (i.e. type $\langle s,\langle e, t\rangle>)$. ${ }^{6}$ Indefinites, in contrast, will be interpreted as formulas (i.e., type $t$ ) containing a variable which must be assigned a value. Correlated with this type difference is the fact that the indefinite introduces a discourse referent (though perhaps a quantificationally or modally subordinated one, see Heim 1982 for further discussion), while the BP does not. ${ }^{7}$

The second assumption is that it must be possible for a predicate like comprar ('to buy') to combine with a property-type expression while retaining fundamentally the same content as when it combines with an ordinary entity-denoting NP. A simple way to do this is to associate Spanish verbal predicates with 'floating' types subject to a special interpretive convention. Specifically: ${ }^{8}$

(13) For all $n$-ary predicates $P(n>1)$, and for all $i, 1 \leq i \leq n$, if $P$ 's $i$-th argument is of type $e$, then $P$ 's $i$-th argument can also be of type $\langle s,\langle e, t\rangle\rangle$.

The interpretation rule for the combination of a predicate $P$ with a propertytype argument $Q^{9}$ will be as in (14):

(14) For all $Q$ of type $\langle s,\langle e, t\rangle\rangle$, and for all $n$-ary predicates $P$ as in (13) with ordered arguments $\left\langle a_{l} \ldots a_{n}\right\rangle,\langle w, g\rangle \in \operatorname{Sat}\left(C+P\left(a_{1}, \ldots Q_{i}, \ldots a_{n}\right)\right)$, iff there is some $x$ and some $g^{\prime}$ (where $g^{\prime}$ agrees with $g$ on all elements in the $\operatorname{Dom}(C)$ ) such that $g^{\prime}(x) \in[[Q]]$ and $\left\langle w, g^{\prime}\right\rangle \in \operatorname{Sat}\left(C+P\left(a_{1}, \ldots x_{i}, \ldots a_{n}\right)\right)$.

6. And I assume, following Carlson (1977), that kinds are entities, though I will not discuss kinds further here.

7. Casting the analysis in terms of unification-based grammar formalism would perhaps sharpen this relationship: for example, BP and indefinite counterparts could be specified with identical values for a CONTENT feature, while only indefinites would receive a value for a REFERENTIAL INDEX feature. Such a formalism could perhaps also allow for a simpler and more general account of the way predicates combine with indefinites and BPs. For example, combining a transitive verb with either an indefinite or BP would have the syntactic effect of saturating the argument corresponding to the position filled by the NP; the semantics could simply unify the content of the NP with that of the verb. In the case of BPs, what would get unified would simply be a condition on the description of whatever individual ultimately satisfies the participant role associated with the BP; in the case of indefinites, there would be an added condition that this individual be a possible value for the referent $x_{i}$ introduced by the indefinite (and which will therefore be novel with respect to the discourse).

8. Since some predicates in Spanish do not allow BP arguments, or allow such arguments only under certain circumstances, perhaps the option of accepting a property-type argument ultimately should not be available to all verbs in the language, contrary to what is proposed in (13). How best to handle the idiosyncratic limitations on the distribution of BPs - whether the conditions are syntactic, semantic, pragmatic or some combination of these is a matter of ongoing research.

9. I assume the syntactic rules of the language will ensure that $Q$ corresponds to an NP as opposed to e.g. an AP or VP. 
This rule is very much in the spirit of Carlson's (1977) interpretation rule for bare plural arguments of stage-level predicates, insofar as any existential force associated with the bare plural comes from the lexical entailments of the predicate, and not from either inherent quantificational force associated with the bare plural or the equivalent of Heim's (1982:Chap. 2) 'text-level existential closure. ${ }^{10}$

Let us now see how these assumptions account for the facts discussed in the previous section. Since indefinites will be treated essentially as in Heim (1982), I will discuss only the BP facts. Consider first the obligatory narrow scope of BPs in sentences such as $(7 b)$, repeated in (15):

(15) A la reunión no asistieron profesores.

at the meeting not attended professors

'The meeting was not attended by (any) professors.'

A Heim-style Logical Form (LF) for this sentence under the analysis proposed here would be translated as in (16), where $x_{i}$ corresponds to a familiar discourse referent and $\wedge^{\wedge} \mathrm{P}$ is the constant corresponding to the property of being a professor:

(16) $\neg\left[\operatorname{meeting}\left(x_{i}\right) \wedge\right.$ attend $\left.\left(\wedge \mathrm{P}, x_{i}\right)\right]$

Following an adapted version of the rules in Heim (1982:363ff.), provided in the Appendix, the context change potential for (15) is as in (17). Since the sentence is quantificationally closed and therefore does not introduce any new, persistent discourse referents, the domain of the file will not change; the resulting satisfaction set will be the complement of the set of world-assignment function pairs that would have satisfied the scope of the negation in (16), most crucially, the second conjunct:

(17) Context change potential for (15):

$\operatorname{Dom}(C+(15))=\operatorname{Dom}(C)$;

$\operatorname{Sat}(C+(15))=\left\{\langle w, g\rangle \in \operatorname{Sat}(C) \mid\right.$ there is no pair $\left\langle w, g^{\prime}\right\rangle$ (where $g^{\prime}$ agrees with $g$ on all elements in $\operatorname{Dom}(C))$ such that $\left\langle w, g^{\prime}\right\rangle \in \operatorname{Sat}\left(\left(C+\right.\right.$ meeting $\left.\left(x_{i}\right)\right)$ $\left.\left.+\operatorname{attended}\left({ }^{\wedge} \mathrm{P}, x_{i}\right)\right)\right\}$.

A world-assignment function pair $\langle w, g\rangle$ will be in $\operatorname{Sat}\left(C+\right.$ attended $\left.\left({ }^{\wedge} \mathrm{P}, x_{i}\right)\right)$ iff there is some $x$ such that $g(x)$ is a professor and attended the meeting in $w$. The complement of this set of world-assignment function pairs will be all those in which there is no such $x$. The effect of narrow scope with respect to negation has thus been achieved. The analysis will work analogously no matter what operator is involved. The obligatory narrow scope of Spanish BPs therefore follows directly, in essentially the same way as it followed on Carlson's analysis of English BPs.

Now consider the second fact discussed above, namely that BPs cannot constitute the primary restriction on adverbial quantification over individuals. We need

10. See also Van Geenhoven (1995) and Glasbey (1998) for very similar proposals. 
to account for the fact that sentences like (11a), repeated here in (18a), have only a reading like that in (18b), and not like that in (18c):

(18) a. Miembros del parlamento comen a menudo en La Panadella. members of-the parliament eat.3pl often in La Panadella 'Members of parliament often eat at La Panadella.'

b. (often $e: C R(e))[(\exists x:$ member-parliament $(x))[\operatorname{eat}(x, \mathrm{p}, e)]]$

c. (often $x$ : member-parliament $(x))[\operatorname{eat}(x, \mathrm{p}, e)]]$

I have said nothing up to this point about the factors that determine whether a constituent can or cannot contribute to the restriction on a quantification. However, I assume that, in principle, nothing arbitrary should prevent a BP from contributing to a quantificational restriction (see Section 4 for more on this issue). Instead, the absence of the reading in (18c) follows from the fact that the BP, in virtue of its semantics (and its concomitant failure to introduce a discourse referent), is unable to restrict quantification in such a way as to yield the reading in (18c).

First let us see how the right reading is obtained. The context change potential for (18a), corresponding to (18b), is as in (19):

(19) Context change potential for (18a):

$\operatorname{Dom}(C+(18 \mathrm{a}))=\operatorname{Dom}(C)$;

$\operatorname{Sat}(C+(18 \mathrm{a}))=\left\{\langle w, g\rangle \in \operatorname{Sat}(C) \mid\right.$ there are many pairs $\left\langle w, g^{\prime}\right\rangle\left(\right.$ where $g^{\prime}$ agrees with $g$ on all elements in $\operatorname{Dom}(C))$ such that $\left\langle w, g^{\prime}\right\rangle \in \operatorname{Sat}(C+C R(e))$ and for which there is also a pair $\left\langle w, g^{\prime \prime}\right\rangle$ (where $g^{\prime \prime}$ agrees with $g^{\prime}$ on all elements of $\operatorname{Dom}(C+C R(e))$ such that $\left\langle w, g^{\prime \prime}\right\rangle \in \operatorname{Sat}((C+C R(e))+$ eat $\left.\left.\left({ }^{\wedge} \mathrm{MP}, \mathrm{p}, e\right)\right)\right\}$

The restriction of the quantification is a contextually-determined set of eventualities (for instance, those in which members of parliament eat); those worldassignment function pairs satisfying the scope of quantification will be just those in which there is an $x$ such that $x$ is in the extension of miembro del parliamento ('member of parliament'), and $x$ is in a situation $e$ of eating at La Panadella. The satisfaction set for the sentence as a whole will include just those pairs $\langle w, g\rangle$ in which there are many eating eventualities involving members of parliament for which such an $x$ can be found. Such a scenario corresponds intuitively to the truth conditions for (18b).

Under the assumption that the BP is interpreted as a property, there is no way to derive the reading in (18c). In order to achieve such a reading, the BP would have to contribute a condition of the form $\operatorname{MP}(x)$, which would serve as the restriction on a generic quantification. However, such a contribution would be tantamount to claiming that the BP has the same interpretation as an indefinite. Analyzing the $\mathrm{BP}$ as a property entails interpreting it as a constant, exactly the same way that a proper name is interpreted, though of a higher type. A constant without the help 
of a variable cannot contribute a condition of the sort needed to restrict the quantification.

Treating the $\mathrm{BP}$ as contributing the distinguishing element in the restriction on quantification over equivalence classes of cases, as in (20), does not work, either. Suppose we try quantifying over cases involving eventualities involving the property of being a member of parliament:

(20) $\left\{\langle w, g\rangle \in \operatorname{Sat}(C) \mid\right.$ there are many pairs $\left\langle w, g^{\prime}\right\rangle$ (where $g^{\prime}$ agrees with $g$ on all elements in $\operatorname{Dom}(C))$ such that $\left\langle w, g^{\prime}\right\rangle \in \operatorname{Sat}\left(C+\operatorname{in}\left({ }^{\wedge} \mathrm{MP}, e\right)\right)$, and for which there is also a pair $\left\langle w, g^{\prime \prime}\right\rangle$ (where $g^{\prime \prime}$ agrees with $g^{\prime}$ on all elements of $\operatorname{Dom}(C+$ $\left.\left.\operatorname{in}\left({ }^{\wedge} \mathrm{MP}, e\right)\right)\right)$ such that $\left.\left\langle w, g^{\prime \prime}\right\rangle \in \operatorname{Sat}\left(\left(C+\operatorname{in}\left({ }^{\wedge} \mathrm{MP}, e\right)\right)+\operatorname{eat}\left({ }^{\wedge} \mathrm{MP}, \mathrm{p}, e\right)\right)\right\}$

It should be obvious that the $\mathrm{BP}$ does not contribute a variable whose value may vary in order to impose a partition on the set of cases being quantified over. Moreover, (20) cannot correspond to (18c) because it does not require the individual men who support the satisfaction of $C+\operatorname{in}\left({ }^{\wedge} \mathrm{MP}, e\right)$ to be distinct in each case. (20) thus could include a pair $\langle w, g\rangle$ for which there are many eventualities involving a member of parliament that happens to be, say, Joan Saura, in which Saura eats at La Panadella. But again this is the reading expressed by (18b), and not (18c).

Although we have not been able to obtain a reading on which the BP is the primary descriptor of the domain of quantification, nothing in principle prevents the BP from contributing a secondary restriction on quantification. And indeed, Spanish BPs can have this function, as illustrated by the sentences in (21a), involving quantification over individuals distinct from those described by the bare plural, and (21b), involving quantification over eventualities:

(21) a. Mucha gente que tiene perros los abandona durante las many people that have dogs 3pl.acc abandon during the vacaciones.

vacations

'Many people that have dogs abandon them (i.e. the dogs they have) during vacation.'

b. Cuando los niños leen libros, normalmente los leen en when the children read books normally 3placc read in voz alta.

voice high

'When children read books, they usually read them (i.e. the books in question) aloud.'

Note that in both cases the BP licenses a subsequent pronoun.

On the analysis proposed here, this licensing cannot be direct, as the BP does not denote the antecedent for the pronoun. Rather, the antecedent must be determined via accommodation. An examination of a wider range of data involving sim- 
ple clauses indicates that this accommodation is strictly local. Consider the sentences in (22). If the BP is not in the scope of any operator or intensional predicate, as in (22a), it will support discourse anaphora to particular individuals, parallel to the case of anaphora above. In contrast, if it is in the scope of an operator or intensional predicate, as in (22b), the only sort of discourse anaphora possible is to the description of the property itself. ${ }^{11}$ If the accommodation licensing the pronoun were global, we would expect to find also a reading on which the pronoun in (22b) picks out specific antiques that Juan wanted to restore; however, this reading is not available.
a. Ayer compré aceitunas, pero no me gustan porqué son yesterday bought olives but not lsg.dat please because are demasiado amargas. too bitter

'Yesterday I bought olives, but I don't like them (i.e. the olives I bought yesterday) because they are too bitter.'

b. Juan quería restaurar muebles de estilo, pero terminó Juan wanted restore.inf furniture of style, but ended vendiéndolos. selling-3pl.acc

'Juan wanted to restore antiques but ended up selling them (i.e. unspecified antiques).'

\section{(adapted from Laca 1996:247)}

This accommodation appears to be facilitated by a combination of the descriptive content of the BP and the fact that sentences like those in (22a) entail the existence of an entity that could support the anaphora in (21). The discourse anaphora associated with BPs in the scope of operators and intensional predicates contrasts with that associated with indefinites. Unlike the pronoun in (22b), that in (23) can refer to specific antiques Juan wanted to restore:

(23) Juan quería restaurar unos muebles de estilo, pero terminó Juan wanted restore.inf a.pl furniture of style but ended selling-them.acc

vendiéndolos.

'Juan wanted to restore some antiques but ended up selling them (either the antiques he wanted to restore, or unspecified antiques).' (adapted from Laca 1996:247)

11. This anaphora is similar to the use of them with a kind as antecedent in sentences like (i), discussed in Carlson (1977):

(i) Laura knows that dinosaurs are extinct, but she still claims she sees them in the backyard. 
This contrast parallels the scope contrast between BPs and indefinites, and is fully expected on the analysis presented here.

This completes the exposition of the basic analysis. I will now discuss briefly some reasons for preferring this treatment of Spanish BPs to one in which they are not distinguished in type from indefinites.

\section{Why not treat BPs as 'special' indefinites?}

One could imagine an alternative to this analysis on which Spanish BPs contributed variables just as do indefinites on a Kamp/Heim-style analysis, in an effort to preserve the essence of Wilkinson's (1991) and Diesing's (1992) treatments of existential bare plurals. Such an alternative would only require that BPs carry the conventional conditions that (1) they must be construed with narrowest possible scope and that (2) they cannot provide the primary restriction on adverbial quantification over individuals (or the distinguishing variable in determining equivalence classes of cases for the purposes of quantification). These characteristics must be stipulated separately because they are logically independent of each other (though looking for empirical evidence that they are independent characteristics is not a trivial matter, for reasons that will be mentioned below). Even if an indefinite were required to take narrow scope with respect to all other operators, it does not follow that the indefinite would be prevented from providing the primary restriction on the most embedded operator. Similarly, one can imagine a special indefinite which is unable for some reason to restrict adverbial quantification (either directly or via distinguishing equivalence classes of cases), and yet which can take, say, wide scope over any operators in the sentence.

While this alternative proposal may appear prima facie more stipulative than the analysis sketched above, there are two ways it could be justified: (1) if BPs (or other classes of indefinites) varied cross-linguistically in their semantics in such a way that these characteristics were in free variation and thus ought not to follow from any deep fact about the BP's semantic type; or (2) if these two characteristics could be made to follow from some other, nonsemantic fact about BPs.

I have not studied the typology of BPs, and so I am not in a position to evaluate directly the first of these possible justifications. ${ }^{12}$ However, we can cast doubt on it by answering two, more fundamental, questions: (1) What is the nature of the idiosyncratic scope restrictions languages encode on particular classes of phrases? And (2) do languages conventionally limit the ability of particular classes of phrases to restrict adverbial quantification?

I strongly suspect that the answer to the second question is negative. As I noted above, there is good evidence that quantificational restrictions are largely prag-

12. [Added 2004] To date I have seen no proposal to treat BPs as varying so freely in these various aspects of their semantics. On the other hand, there have been various proposals for treating other examples of bare singular or bare plural nominals as property denoting - see for instance Rullmann and You (2003), Farkas and de Swart (this volume), Espinal (this volume), and the various works mentioned in the preface to this paper. 
matically determined. Those potential cases that I know of where conventionalization might play a role in determining the ability of a constituent to contribute to quantifier restrictions fall into two categories. They may involve the positive requirement that some constituent provide the primary restriction on a quantification, rather than a negative requirement that the constituent not do so. Nominal complements to quantificational determiners might be such a case in point (though see Barker 1994 for arguments that even determiner quantification is not conventionally limited in this way). Or, they may involve restrictions imposed in virtue of the informational import of the syntactic position or phonological marking of a constituent, e.g. when it is clefted. Note, however, that this latter type of limitation is not a fact about particular constituents themselves (as is the case with the quantificational restrictions imposed on Spanish BPs), but rather a fact about certain linguistic environments or markings. It would be undesirable to idiosyncratically limit the ability of Spanish BPs to restrict adverbial quantification if natural languages generally did not countenance such limitations.

What about scope? A superficial survey of the literature suggests that putative cases of idiosyncratic scopal restrictions on NPs are always sensitive to particular characteristics of particular operators - e.g. monotonicity, in the case polarity items (see Ladusaw 1979); intensionality, in the case of NPs modified by subjunctive relative clauses (see Farkas 1985); or distributivity, in the case of NPs such as Hungarian reduplicated indefinite (see Farkas 1997). Moreover, such NPs must be in the scope of the right sort of operator to be licensed at all. The narrowest scope requirement on Spanish BPs differs in both respects from these examples. First, it applies to all operators, irrespective of the characteristics of those operators; second, Spanish BPs do not require the presence of any superordinate operator at all in order to be licensed. Thus, BPs would constitute a highly unusual type of scopally restricted indefinite.

Let us consider, then, how one could try to justify the analysis of BPs as 'special' indefinites without appeal to an idiosyncratic semantics. The only plausible strategy ${ }^{13}$ would involve trying to make their special semantic characteristics follow from a constraint on their syntax, in conjunction with a theory of the syntax/semantics interface like Diesing's (1992) Mapping Hypothesis, stated in (24):

(24) Material from [inside] VP is mapped into the Nuclear Scope [of a higher quantifier]

Material from ["higher up," outside VP] is mapped into a Restrictive Clause

Suppose we set aside the highly theory-internal nature of this proposal and look for evidence that Spanish BPs must always appear within VP; if so, the facts

13. It does not seem possible that the behavior of BPs could be made to follow from any special information-theoretic properties since it has been shown that the informational function of an NP is independent of both its scope (see e.g. Kadmon and Roberts 1986) and its ability to function as a restriction on quantification (see e.g. Vallduví 1992). 
discussed in section 2 could be made to follow. The problem with such an approach, however, is that there is no evidence that Spanish BPs differ at all in their syntax from indefinite NPs, despite claims in the literature to the contrary (see Fontana and McNally 1995 for discussion).

Although this discussion has been necessarily abbreviated, I hope to have at least pointed to some reasons why treating BPs as 'special' indefinites is not an attractive option. ${ }^{14}$

\section{Conclusion: Some final support for the property analysis of BPs}

Now let me close by briefly mentioning three positive reasons to prefer the property analysis of BPs.

First, the analysis accounts quite straightforwardly for all the Spanish facts discussed above. At the moment I do not know of any empirical problems that it faces.

Second, treating BPs as properties amounts to the simplest analysis. BPs must be interpretable as properties in order to combine with determiners in Spanish, anyway; consequently, the analysis amounts to the claim that they are semantically unambiguous (and depending on one's theory of the syntax/semantics interface, syntactically unambiguous as well). The only innovation needed involves assigning predicates floating types. However, such a move might be justified by looking for examples in natural language of predicates that select specifically for propertytype arguments, carrying the same sort of truth conditions needed for the above analysis of Spanish BPs. If we found such predicates, we could view the use of floating types made here as a generalization of an option that is independently needed in the grammars of natural languages. ${ }^{15}$ I have argued elsewhere (McNally 1992) that the there-existential predicate (and its counterpart haber in Spanish) is exactly this kind of predicate.

Finally, the property analysis seems typologically more promising and theoretically more interesting. There are a number of reasons why this is so; I can only mention a few here. First, it predicts that, if BPs are relatively uniform in their semantics crosslinguistically, they will consistently have the scopal and quantification restriction characteristics attested in Spanish. The property analysis thus leads to stronger predictions about the behavior of BPs universally. Conversely, it raises the expectation that languages might regularly make use of property-type expressions as linguistic arguments (whether those expressions are BPs or are marked in some other fashion, such as perhaps partitive de phrases in French), and that such expressions should have the same constellation of characteristics as Spanish BPs.

14. Another option, which is to treat BPs as verb modifiers (cp. e.g. the treatment of NPs with 'weak' case in de Hoop (1992)), cannot be considered here due to lack of space. However, note that there is no obvious evidence supporting the assignment of a modifier type to BPs.

15. [Added 2004] The obligatorily incorporating predicates in West Greenlandic discussed in Van Geenhoven (1998) are one such example. 
Second, the analysis suggests why BPs resemble incorporated nominals (see Masullo 1992, Van Geenhoven 1995) without requiring that they be incorporated in any interesting syntactic or morphological sense - a desirable result since Spanish BPs are syntactically quite independent. On the view taken here, incorporated nominals (which, like BPs, are generally determinerless; see e.g. Mithun 1984) and BPs would resemble each other in their semantic type - both interpreted as properties, as e.g. van Geenhoven $(1993,1995)$ proposes - and therefore likely to combine with predicate denotations via similar semantic operations. Although the special pragmatic functions of incorporation are still poorly understood, given the fact that it is so widespread cross-linguistically, it seems quite plausible that speakers of languages without morphological or syntactic incorporation constructions would find use for other linguistic devices (such as BPs with their special semantics) that would allow them to approximate the pragmatic functions of incorporation.

Third, the analysis raises questions about our understanding of the semantics of English BPs. In particular, we should reconsider in light of the results presented here the consequences of the fact that English BPs can denote kinds, in an effort to see whether the availability of this denotation accounts for the various differences between English and Spanish BPs. Such a reevaluation of the literature on English BPs could have important implications for our understanding of the contribution of kind-denoting expressions to characterizing sentences.

Linguists have uncovered increasing evidence over the past several years that natural languages make considerable use of property-type nominals. This evidence emphasizes the need for a formal semantics that can make use of the interpretations of such expressions without paradox or loss of generalization. The use of properties leads to new ways of thinking about the existential force we intuitively associate with NPs, about the ways in which discourse anaphora is licensed, about what it means for an NP to be 'weak' (see Ladusaw 1994, McNally 1998, and even about intensionality (see Zimmermann 1993). I hope that this preliminary analysis of the Spanish facts and the theoretical and descriptive issues it raises will encourage further development of semantic theories that can make insightful use of property-type argument expressions.

\section{Appendix}

General interpretation rules, relative to a Model $M=\langle E,[[\cdot]]\rangle, E$ a set of entities, $[[\cdot]]$ an interpretation function (adapted from Heim (1982:363ff.):

1. Let $\varphi$ be an atomic formula of the form $\beta\left(\alpha_{1}, \ldots \alpha_{n}\right)$. Then:

$\operatorname{Dom}(C+\varphi)=\operatorname{Dom}(C) \cup\left\{\alpha_{1}, \ldots \alpha_{n}\right\}$;

$\operatorname{Sat}(C+\varphi)=\left\{\langle w, g\rangle \in \operatorname{Sat}(C) \mid\left\langle g\left(\alpha_{1}\right), \ldots g\left(\alpha_{\mathrm{n}}\right)\right\rangle \in[[\beta]]\right.$ in $\left.w\right\}$.

2. Let $\varphi$ be a formula with immediate constituent formulas $\varphi_{1} \ldots \varphi_{n}$ in that order. Then:

$\operatorname{Dom}(C+\varphi)=\operatorname{Dom}\left(\left(C+\varphi_{1}\right) \ldots+\varphi_{n}\right)$;

$\operatorname{Sat}(C+\varphi)=\operatorname{Sat}\left(\left(C+\varphi_{1}\right) \ldots+\varphi_{n}\right)$. 
3. Let $\varphi$ be a quantified formula consisting of a binary quantificational operator $Q$ and a complex formula consisting of immediate subformulas $\varphi_{1}$ and $\varphi_{2}$, in that order. Then:

$\operatorname{Dom}(C+\varphi)=\operatorname{Dom}(C)$;

$\operatorname{Sat}(C+\varphi)=\left\{\langle w, g\rangle \in \operatorname{Sat}(C) \mid\right.$ for $Q$-many pairs $\left\langle w, g^{\prime}\right\rangle$ (where $g^{\prime}$ agrees with $g$ on all elements in $\operatorname{Dom}(C))$ such that $\left\langle w, g^{\prime}\right\rangle \in \operatorname{Sat}\left(C+\varphi_{1}\right)$, there is some $<w, g^{\prime \prime}>$ (where $g^{\prime \prime}$ agrees with $g^{\prime}$ on all elements of $\left.\operatorname{Dom}\left(C+\varphi_{1}\right)\right)$ such that $\left.\left\langle w, \mathrm{~g}^{\prime \prime}\right\rangle \in \operatorname{Sat}\left(\left(C+\varphi_{1}\right)+\varphi_{2}\right)\right\}$.

4. Let $\varphi$ be a quantified formula consisting of a negator and the formula $\psi$. Then: $\operatorname{Dom}(C+\varphi)=\operatorname{Dom}(C)$;

$\operatorname{Sat}(C+\varphi)=\left\{\langle w, g\rangle \in \operatorname{Sat}(C) \mid\right.$ there is no pair $\left\langle w, g^{\prime}\right\rangle$ (where $g^{\prime}$ agrees with $g$ on all elements in $\operatorname{Dom}(C))$ such that $\left.\left\langle w, g^{\prime}\right\rangle \in \operatorname{Sat}(C+\psi)\right\}$.

\section{References}

Alonso, Amado (1954). «Estilística y Gramática del Artículo en Español». In: Alsono, Amado. Estudios lingüísticas. Temas españoles. Madrid: Gredos.

Barker, Chris (1994). «Unselective Determiners». In: Duncan, Erin; Farkas, Donka; and Spaelti, Philip (eds.). Proceedings of WCCFL 12. Stanford, CA: CSLI, pp. 485-500.

Bosque, Ignacio (1996). El Sustantivo Sin Determinación. La Ausencia de Determinación en la Lengua Española. Madrid: Visor Libros.

Carlson, Gregory (1977). Reference to Kinds in English. University of Massachusetts Amherst, doctoral dissertation. Published 1980 by Garland Press, New York.

Chierchia, Gennaro (1998). «Reference to Kinds Across Languages». Natural Language Semantics 6: 339-405.

Chung, Sandra (2000). «On Reference to Kinds in Indonesian». Natural Language Semantics 8: 157-171.

Chung, Sandra; Ladusaw, William A. (2004). Restriction and Saturation. Cambridge, MA: MIT Press.

Condoravdi, Cleo (1994). Descriptions in Context. Yale University, doctoral dissertation. Diesing, Molly (1992). Indefinites. Cambridge, MA: MIT Press.

de Swart, Henriëtte (1993). Adverbs of Quantification: A Generalized Quantifier Approach. New York: Garland.

Dobrovie-Sorin, Carmen (1997). «Existential Arguments and Existential Predicates». In: Lawson, Aaron (ed.). Proceedings of Semantics and Linguistic Theory VII. Ithaca, NY: CLC Publications, pp. 117-134.

Dobrovie-Sorin, Carmen; Laca, Brenda (1998). «La Génericité entre la référence à l'espèce et la quantification générique». In: Patrick Sauzet (ed.). Actes de Langues et Grammaires III. Saint-Denis: Université Paris 8, pp. 163-177.

Dobrovie-Sorin, Carmen; Laca, Brenda. (2003). «Les Noms Sans Déterminant Dans les Langues Romanes.». In: Godard, Danièle (ed.). Les Langues Romanes. Problèmes de la Phrase Simple. Paris: Editions du CNRS, pp. 235-281.

Espinal, Maria Teresa (this volume). «Lexicalization of Light Verb Structures and the Semantics of Nouns». 
Farkas, Donka (1985). Intensional Descriptions and the Romance Subjunctive Mood. New York: Garland Press.

Farkas, Donka (1997). «Dependent Indefinites». In: Corblin, Francis; Godard, Danièle; Marandin, Jean-Marie (eds.). Empirical Issues in Formal Syntax and Semantics. Bern: Peter Lang, pp. 243-268.

Farkas, Donka; de Swart, Henriëtte (2003). The Semantics of Incorporation. Stanford, CA: CSLI Publications.

Farkas, Donka; de Swart, Henriëtte (this volume). «Incorporation, Plurality, and the Incorporation of Plurals: a Dynamic Approach».

Fontana, Josep M.; McNally, Louise (1995). «Unaccusativity and the Distribution of Bare Plurals in Catalan and Spanish». Presented at the LSA Annual Meeting, New Orleans, LA.

Glasbey, Sheila (1998). «A Situation-Theoretic Interpretation of Bare Plurals». In: Ginzburg, Jonathan; Khasidashvili, Zurab; Vogel, Carl; Lévy, Jean-Jacques; Vallduví, Enric (eds.). The Tbilisi Symposium on Logic, Language and Computation: Selected Papers. Stanford, CA: CSLI Publications, pp. 35-54.

Groenendijk, Jeroen; Stokhof, Martin (1990). «Dynamic Montague Grammar». In: Kálman, Laszlo; Pólos, Laszlo (eds.) Papers from the Second Symposium on Logic and Language. Budapest: Akadémiai Kiadó, pp. 3-48.

Heim, Irene (1982). The Semantics of Definite and Indefinite Noun Phrases. University of Massachusetts Amherst, doctoral dissertation. Published 1989 by Garland Press, New York.

de Hoop, Helen (1992). Case Configuration and Noun Phrase Interpretation. University of Groningen, doctoral dissertation. Published 1996 by Garland Press, New York.

Kadmon, Nirit; Roberts, Craige (1986). «Prosody and Scope: The Role of Discourse Structure». In: Farley, A; Farley, P; and McCullough, K.-E. (eds.). CLS 22, Part 2: Papers from the Parasession on Pragmatics and Grammatical Theory. Chicago: Chicago Linguistics Society, pp. 16-28.

Kamp, Hans (1984). «A Theory of Truth and Interpretation». In Groenendijk, Jeroen; et al. (eds.). Truth, Interpretation, and Information, Dordrecht: Foris, pp. 1-41.

Kratzer, Angelika (1995). «Stage-Level and Individual-Level Predicates». In Carlson, Greg; Pelletier, Francis J. (eds.). The Generic Book. Chicago: University of Chicago Press, pp. 125-175.

Krifka, Manfred (2003). «Bare Plurals: Kind-Referring, Indefinites, Both, or Neither?» Paper presented at the Fifth Paris Syntax and Semantics Colloquium, October 2003.

Laca, Brenda (1994). «¿Existen los Verbos Presentativos?»In: Verbo e Estruturas Frásicas. Actas do IV Colóquio Internacional de Linguística Hispánica. Porto: Facudade de Letras do Porto, pp. 141-152.

Laca, Brenda (1996). «Acerca de la Semántica de los 'Plurales Escuetos' del Español». In: Bosque, Ignacio (ed.). El Sustantivo Sin Determinación. La Ausencia de Determinación en la Lengua Española. Madrid: Visor Libros, pp. 241-268.

Ladusaw, William A. (1979). Polarity Sensitivity as Inherent Scope Relations. University of Texas at Austin, doctoral dissertation.

Ladusaw, William A. (1994). «Thetic and Categorical, Stage and Individual, Weak and Strong». In: Harvey, Mandy; Santelmann, Lynn (eds.). Proceedings of Semantics and Linguistic Theory IV. Ithaca, NY: Cornell University DMLL, pp. 220-229. 
Masullo, Pascual (1992). Incorporation and Case Theory in Spanish: A Crosslinguistic Perspective. University of Washington, doctoral dissertation.

McNally, Louise (1992). An Interpretation for the English Existential Construction, UCSC, doctoral dissertation. Published 1997 by Garland Press, New York.

McNally, Louise (1995). «Using Property-Type NPs to Build Complex Event Descriptions». Presented at the 4th CSLI Workshop on Logic, Language, and Computation, Stanford, CA.

McNally, Louise (1998). «Stativity and Theticity». In: Rothstein, Susan (ed.). Events and Grammar, Dordrecht: Kluwer, pp. 293-307.

McNally, Louise; Van Geenhoven, Veerle (1997). «Redefining the Weak/Strong Distinction». Paper presented at the Second Paris Syntax and Semantics Colloquium.

Mithun, Marianne (1984). «The Evolution of Noun Incorporation». Language 60:847-94.

Rullmann, Hotze; You, Alia (2003). «Bare Nouns and the Semantics of Number in Mandarin Chinese». Paper presented at the Fifth Paris Syntax and Semantics Conference, October 2003.

Vallduví, Enric (1992). The Informational Component. New York: Garland Press.

Van Geenhoven, Veerle (1993). «Noun Incorporation from a Semantic Point of View». In: Buszard-Welcher, Laura; Wee, Lionel; and Weigel, William (eds.). Proceedings of the $18^{\text {th }}$ Annual Meeting of the Berkeley Linguistics Society. Berkeley, CA: Berkeley Linguistics Society, pp. 453-467.

Van Geenhoven, Veerle (1995). «Semantic Incorporation: A Uniform Semantics for West Greenlandic Noun Incorporation and West Germanic Bare Plural Configurations». In: Dainora, Audra; Hemphill, Rachel; Luka, Barbara; Need, Barbara; Pargman, Sheri (eds.). Papers from the $31^{\text {st }}$ Meeting of the Chicago Linguistics Society. Chicago: Chicago Linguistics Society, pp. 171-186.

Van Geenhoven, Veerle (1998). Semantic Incorporation and Indefinite Descriptions. Stanford, CA: CSLI Publications.

Van Geenhoven, Veerle (2000). Pro Properties, Contra Generalized Kinds. In: Jackson, Brendan; Matthews, Tanya, (eds.). Proceedings from Semantics and Linguistic Theory X. Ithaca, NY: CLC Publications, pp. 221-238.

Van Geenhoven, Veerle; McNally, Louise (in press). «On the property analysis of opaque complements». Lingua.

Wilkinson, Karina (1991). Studies in the Semantics of Generic Noun Phrases. University of Massachusetts Amherst, doctoral dissertation.

Zimmermann, Thomas Ede (1993). «On the Proper Treatment of Opacity in Certain Verbs». Natural Language Semantics 1:149-179. 